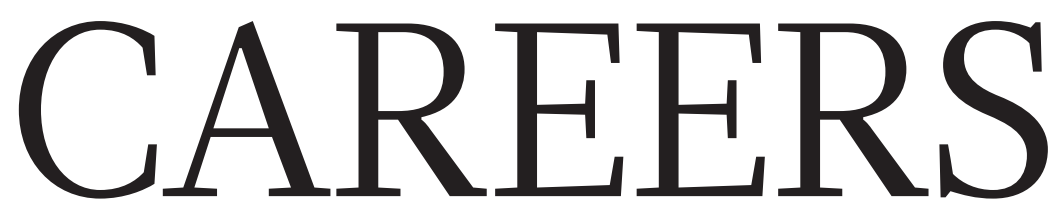

CONFERENCE QUESTIONS Men ask them, women don't. Why? p.451
Education China's appeal explained $\mathbf{p . 4 5 1}$
HARASSMENT TALE Researcher addresses immigration rally $\mathbf{p . 4 5 1}$

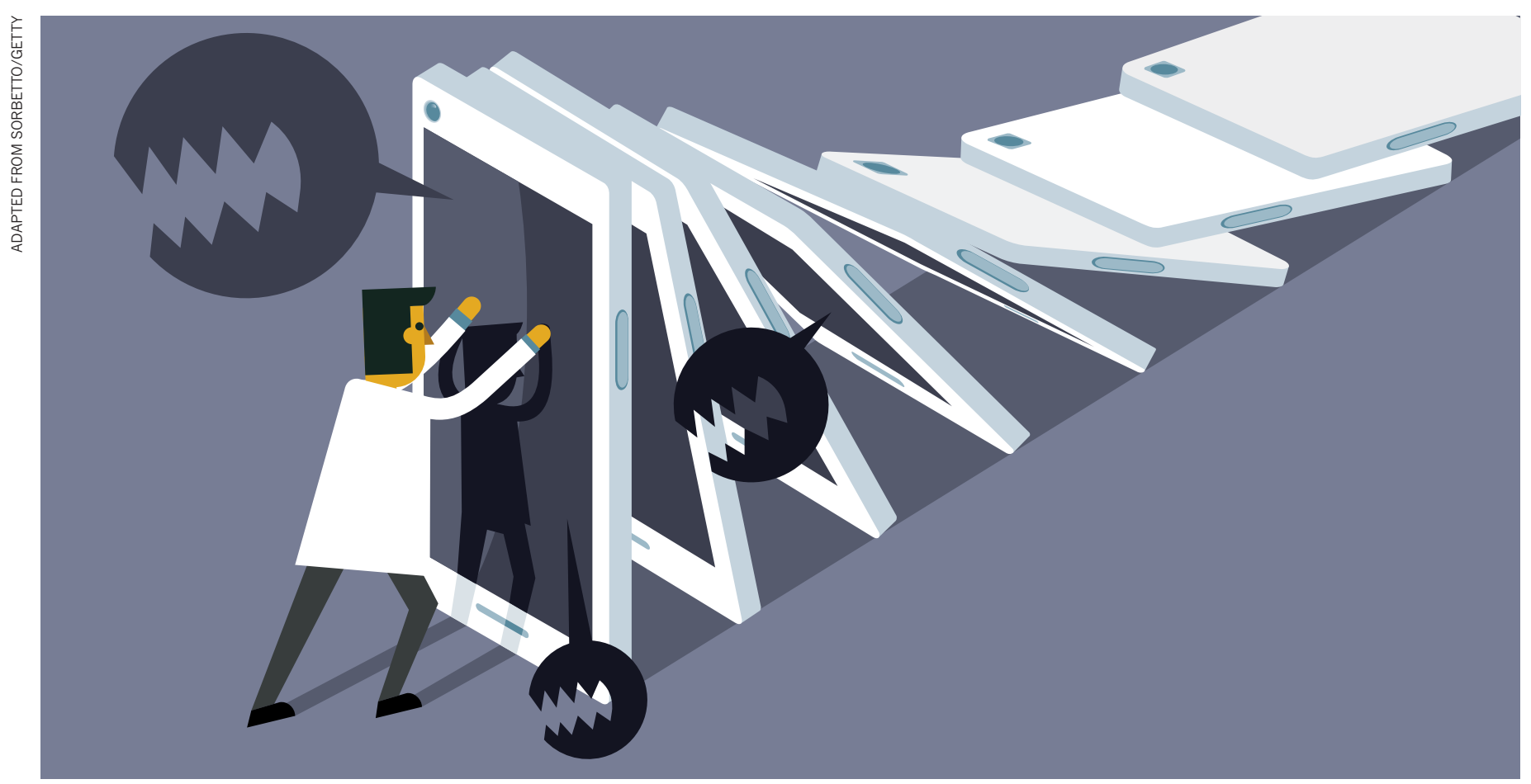

\title{
Tackling harassment
}

\section{Three real-life stories of online abuse - and how scientists got through it.}

$\mathrm{R}$ esearchers who study topics such as climate change and vaccines can become targets of online behaviour ranging from threatening e-mails to coordinated social-media attacks. Nature asked researchers who have been digitally harassed what they've learnt from the experience.

\section{DAVID KEITH Engage judiciously}

Environmental scientist, Harvard University, Cambridge, Massachusetts

I do solar geoengineering experiments notably, researching the chemical impacts of reflective particles that may be sprayed into the stratosphere to minimize incoming solar radiation interact with themselves and other compounds in the atmosphere. I make a distinction between harassers - people who send me more than 100 e-mails per year - and people in the mainstream environmentalscience community who don't agree with my research.

I don't always engage with harassers. I mostly ignore the harassing tweets. The e-mails are harder to ignore - they seem more personal, so I do respond to quite a few, and sometimes I can change the senders' minds.

Over the past decade or so, I've been harassed by people who believe in the 'chemtrail' conspiracy theory - which proposes that long-lasting condensation trails left behind by aircraft are evidence that governments deliberately spray chemicals for nefarious purposes. Around $20-30 \%$ of the US population takes seriously the idea that these purported chemical releases might be for solar-radiation management, human-population control or chemical warfare. I estimate that about half of all tweets around solar geoengineering are in connection with chemtrails.

Routinely, I receive violent, sometime hideously anti-Semitic voicemails, e-mails and letters. A decade ago, I called campus security twice when the harasser became threatening, but nobody has ever been physically violent.

There is a huge gap between online rage and in-person rage. That said, security people at my institution routinely install office alarms, and they advised me to take common-sense steps - for example, to lock my door and pay attention to strangers. I also have conversations with conference organizers before meetings to make sure somebody knows the phone number for campus police in case there is a threat.

When someone sends a hateful thing, I'll ask if that made them feel good. I also ask why they think I'm evil and that I "murder kids". I remind them that I'm a human being, and that I have kids, too. I tell them that I think they've been fooled by some nonsense on 
the Internet, and that they are welcome to talk to me about climate change or geoengineering experiments designed to mitigate climate change. A couple of times, the aggressor has apologized.

The biggest challenge for democracy is learning how to lessen the number of people who believe things that are objectively wrong. I don't think that hiding from it and pretending it isn't there is a good idea. Vilifying people who hold those ideas is not a good approach either. We can't see them all as the enemy.

Instead of trying to change people's minds by telling them they are wrong because an expert says so, I try to question them in a way that shows I take their concerns seriously and reveals how their argument falls apart under scrutiny. In the case of chemtrails, I ask where the supply chains are for the poison, how the dispersal devices are engineered, how all of this has been kept secret for so long and, finally, what the motive is.

Approach debates with caution. They can be useful - but scientists are accustomed to ground rules of honesty and logic in debates, and it's tough to debate with people who are not using honesty and logic. Don't panic if you're being harassed online. The harassment ultimately is not about you, even if it seems personal. Be judiciously willing to respond.

Still, in the end you might have to make a decision. I have upfront conversations about this with postdocs and graduate students, and I encourage them to think through the pros and cons of working in this field. The upside is that it's a new, growing field. The downside is the criticism and polarization. I warn people that hard policy debates are part of this field right now, and that if students don't want to be involved, it might not be the right field for them.

\section{JOANNA HAIGH Play it straight}

\author{
Atmospheric physicist, \\ Imperial College London
}

Harassment, usually by e-mail or attacks through blogposts, comes in waves. I probably get about 100 messages a year. It usually follows statements I've made on the radio or in the press about climate change, or after something has appeared on a climate-change denier website. It can be a range of things - from "You've got it all wrong" and "You are making all of this up" - to extremely rude, offensive personal attacks.

Many of the comments about me have gendered overtones, referring to me as "priggish" or "that woman", or telling me to "stick with flower-arranging". The people who give their names - and many don't - are always men. The worst offender doesn't give a name and has sent about a dozen multi-page screeds.
I have rules of engagement. I try to engage but only with people who haven't been offensive. I have a brief fact sheet on the truth about global warming. If they ask scientific questions, I take a stab at answering them. I never respond to anything personal. I have had one or two write back and thank me for clarifying. Responding to these messages takes a lot of time and energy. At times, it can be a whole day's worth of answering.

Because of the time it takes and the harassment, I am not on Twitter. I know people who do a great job on Twitter, and I'm pleased they take it on. I don't think we can ignore people without being labelled arrogant. I am paid by the public purse, and I have a responsibility to explain to people about the work I do.

I worry about younger scientists who can find themselves targets for attacks they are unprepared to handle. My advice is simple: play it straight. Don't rise to the bait. Explain politely what you understand and what perhaps they have misunderstood. If they are offensive, do not respond.

\section{CHIRISTINE LATTIN Be transparent}

\section{Environmental physiologist, Louisiana State University, Baton Rouge}

In 2017, while I was a postdoc at Yale University in New Haven, Connecticut, I started getting e-mails that claimed that my research was cruel and pointless. I use wild birds to study stress hormones and neurotransmitters. An organization made misleading claims about my work that led to hundreds of harassing messages. Some included death threats.

It has been stressful and challenging, but these harassers' efforts to shut down my research and to silence me have not been successful.

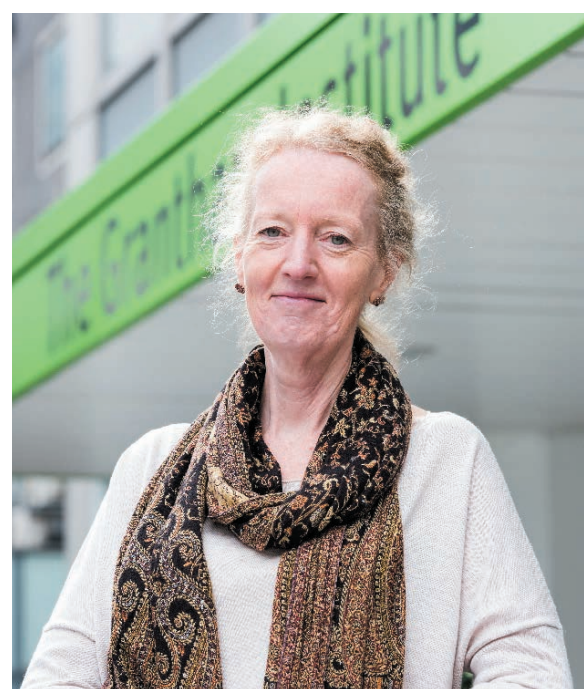

If offensive, do not respond, advises Joanna Haigh.
I was advised to let it blow over and not respond, but that didn't seem to make things better, and it might have made them worse. I decided to defend myself and get different information out there regarding these claims. So I started talking to journalists about my work and speaking up on social media. Taking ownership of my own story made me feel like less of a victim. It's crucial to be open and transparent about our work and advocate for its importance.

I address the false claims directly when possible. I make clear how and why I do this work and that those of us doing animal research receive a ton of oversight. I explain that a lot of people are in place to make sure the animals are taken care of, that suffering is minimized and that the research is justified. For example, every study I do is approved by a university Institutional Animal Care and Use Committee, and both universities I have worked for are accredited by the Association for Assessment and Accreditation of Laboratory Animal Care International. All my research complies with the Ornithological Council's Guidelines for the Use of Wild Birds in Research.

The worst harassment I've had was on Facebook, so I unplug from social media and spend time with my family, friends and pets.

I also reassessed my professional web page. Although I thought I was being so open by making my papers available and creating a statement of my research, the language on my website was technical and not accessible to people at all. I got rid of the jargon and worked with a communications professional to explain clearly the reasons for my research.

I also have a 'frequently asked questions' section to address specific, often-repeated claims, such as 'animal research is unnecessary'. In my response, I point out that although non-animal methods such as cell culture or computer models can be excellent, they have limitations. I also share how I have pioneered less-invasive ways of studying stress as well as new imaging techniques for studying the brain and body. That is the most visited portion of my website. Now, if people Google me, they see two sides of the story.

Do not be afraid to ask for or accept help. I study stress. Exercise helps you to cope with stress. Tell people about what is happening to you and get support from family, friends, colleagues and current and former principal investigators. I have received a lot of messages of support, which has really helped.

There are also specific organizations Speaking of Research, for example - that can offer support. That group helped me to put together rebuttals to the campaign organization's claims. And its director reminded me not to take the harassment personally, because it isn't about me.
INTERVIEWS BY VIRGINIA GEWIN Interviews have been edited for length and clarity. 
Immigrant defender

\begin{abstract}
Born in Sri Lanka, Ashani Weeraratna was raised in Lesotho in southern Africa and moved to the United States in 1988 to pursue an undergraduate science degree. Now a skin-cancer researcher at the Wistar Institute in Philadelphia, Pennsylvania, she has experienced harassment during her three decades in the country. An escalation in incidents prompted her to address a rally protesting against family separations.
\end{abstract}

\section{Describe your most recent experience of harassment.}

In April, I was in a grocery checkout line when someone told me that people like me are from shithole countries and live like animals. In January, I posted on Twitter about being a principal investigator and mentor, and someone asked why I was not taking my science back to my home country. I explained that I am a citizen, that I think the United States is the best place to do science, and that my husband and daughter also live here. The person told me I should leave jobs available for US postdocs. I blocked her when she took a screenshot of my profile photo and one of me with my daughter, whom she referred to as an 'anchor baby' (a pejorative term used to describe a child born in a country with birthright citizenship to a non-citizen mother).

\section{Was the harassment different before the} change in US administration in January 2017? As a more-junior scientist, I thought of myself as an overlooked voice - a woman of colour doing science. It wasn't so much harassment before then as it was not being taken seriously. There were instances, for example after the terrorist attacks on 11 September 2001, when a couple of random people spat at me and said horrible things like, "Go home, dirty Arab." I tried not to let it bother me back then. It's different now, though, because I have a biracial daughter to protect.

\section{How did you come to speak at a pro-immigration rally?}

The Trump administration's policies including the ban on travel from some Muslim-majority countries and possibly rescinding the visas that allow spouses of immigrants to work - are affecting science. Border policies that separate families and incarcerate children, as well as the dehumanizing, divisive language, also bother me. I had one talented collaborator from Syria who was at Wistar for four years on a work visa. But now her visa keeps getting denied. When our Democratic state senator,

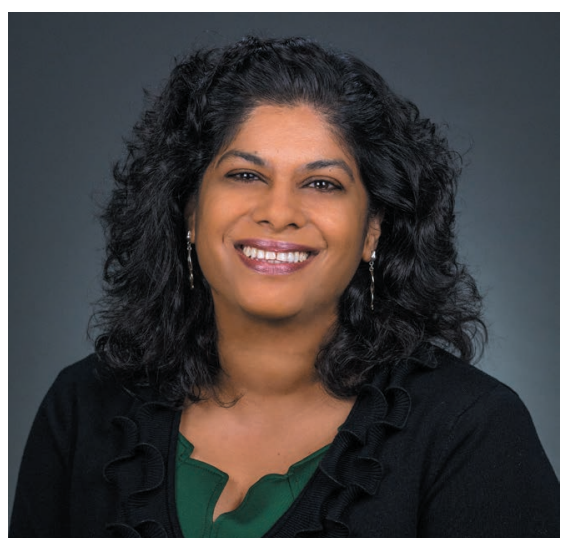

Daylin Leach, asked me to speak at a rally on 30 June to support immigrants and protest against family separations, I had to think about it. But I decided the public needed to understand that these policies hugely affect biomedical research. More than $40 \%$ of the US cancer-research workforce is made up of immigrants. At Wistar, 289 employees are from more than 20 different countries.

\section{Were you concerned about participating?} I worried that, by speaking out, I could jeopardize my federal grants, which support my lab, my students and my institute. I received legal advice that as long as I spoke as a private citizen, I'd be fine. I also talked it over with my husband, a cautious person, who said I needed to be on the right side of history.

\section{What was the reaction to your speech?}

The positive response was overwhelming. I posted a video of my talk on Facebook and friends encouraged me to make it public. It's had more than 4,000 views so far.

\section{What did you share at the rally?}

I grew up in landlocked Lesotho. To get medical training, I would have had to go to South Africa, a country that had apartheid and was segregated in the 1980s. I saw limited opportunities to pursue my dream of being a cancer researcher as a woman of colour there. When I came to the United States for college, to my mind, the country was a bastion of free speech and a great melting pot. To feel like that's being reversed so quickly is frightening and discouraging. I implored politicians to do what they can to ensure that the American dream doesn't become an American nightmare.

\section{INTERVIEW BY VIRGINIA GEWIN}

This interview has been edited for length and clarity.

\section{EDUCATION \\ China calling}

Universities and research institutions in China that have reputations of excellence, or are highly ranked by external organizations, are among the draws for undergraduate and postgraduate international students who are flocking to the country, according to a report in the Journal of Studies in International Education (W. Wen \& D. Hu J. Stud. Int. Educ. http://doi.org/cvfs; 2018). The study finds that since 1995, the number of international students in China has grown 12 -fold, from 36,855 to 442,773 . More than half of those students are from other Asian nations. The authors found that these students, apart from those from Japan, were more concerned with the reputation or ranking of Chinese institutions than were their counterparts from North America, Europe and sub-Saharan Africa. The study, based on survey results and interviews with 30 international students, also found that China's cost of living, admission policies for international students and scholarship programmes increased the nation's appeal to foreign students. The government offers roughly US\$300 million in scholarships to international students each year.

\section{CONFERENCES}

\section{Silence is not golden}

That male speakers outnumber female speakers at seminars and conferences has been a long-standing issue in science, but a gender gap exists on the other side of the lectern, too. Male conference attendees are about 2.5 times more likely than their female counterparts to ask questions of a speaker or panel after a presentation, a study in PLoS One has found (A. Carter et al. PLoS One 13, e0202743; 2018). The authors collected observational data at 247 departmental seminars, hosted at 35 institutions in 10 countries. They also carried out an online survey to gauge how researchers felt about asking questions. By analysing the responses from 509 researchers around the world, the authors found that women were significantly more likely than men to say that they had kept silent because they were unsure whether their question was appropriate, or because they did not have enough "nerve" to ask it. Lead author Alecia Carter, a behavioural ecologist at the University of Montpellier in France, and her co-authors suggest that women might be more likely to raise their hands if organizers allotted more time for questions, or scheduled a short break first for attendees to gather their thoughts. 